E3S Web of Conferences 1, 05001 (2013)

DOI: $10.1051 / \mathrm{e} 3$ sconf/20130105001

(C) Owned by the authors, published by EDP Sciences, 2013

\title{
Comparison of the extraction efficiencies of different leaching agents for reliable assessment of bio-accessible trace metal fractions in airborne particulate matter
}

\author{
$\underline{\text { A. Mukhtar }}^{1}$ and A. Limbeck $^{2}$ \\ ${ }^{1}$ Division of Science and Technology, University of Education, Lahore, Pakistan \\ ch_mazam@hotmail.com \\ ${ }^{2}$ Institute of Chemical Technologies and Analytics, Vienna University of Technology, Vienna, Austria, \\ alimbeck@mail.zserv.tuwien.ac.at
}

\begin{abstract}
In present study, an in-vitro physiologically based extraction test has been applied for extraction of bio-accessible trace metal fractions in airborne particulate matter (APM) samples collected from different urban sites in Austria and Pakistan using the leaching agents $\mathrm{H}_{2} \mathrm{O}$, sodium chloride, ammonium acetate, ammonium citrate, synthetic gastric juice and artificial lung fluids. Obtained extracts were then measured using an ETV-ICP-OES procedure which allowed highly sensitive measurement of dissolved analytes even in the presence of leaching agents. Derived results indicated that the investigated leaching agents extract different amounts of trace metals. In general, leaching agents with organic nature yielded comparatively greater extractable and thus bio-accessible trace metal fractions to that of simple solvents like $\mathrm{H}_{2} \mathrm{O}$ or aqueous $\mathrm{NaCl}$ solution. With water, only $26.3 \pm 4.0 \%$ of $\mathrm{Cd}$ was found to be bio-accessible whereas $88.4 \pm 24.8$ of $\mathrm{Cd}$ was obtained as bio-accessible fraction with the use of synthetic gastric juice. The concentrations of bio-accessible metal fractions varied from $0.4 \mathrm{ng} \mathrm{m}^{-3}(\mathrm{Cd})$ to $714 \mathrm{ng} \mathrm{m}^{-3}(\mathrm{Zn})$ and $0.3 \mathrm{ng} \mathrm{m}^{-3}$ (Cd) to $190 \mathrm{ng} \mathrm{m}^{-3}(\mathrm{Zn})$ for PM10 samples collected from Karachi (Pakistan) and Graz (Austria) respectively.
\end{abstract}

Key words: Bio-accessibility; trace metals; airborne particulate matter; synthetic body fluids

\section{Introduction}

In recent years, many toxicological studies have implicated metal contents as a possible harmful component of APM (Prieditis and Adamson, 2002) since they can be absorbed into human tissues during breathing especially particles with an aerodynamic diameter less than 10 microns (PM10). The toxicity of metal depends upon its species that are present. Thus, for risk assessment of metal toxicity, it is important to determine bio-accessible concentrations instead of total metal contents (Michelozzi et al., 1998).

Particles in the 2.5 - to $10-\mu \mathrm{m}$ size fraction are in most cases deposited in the tracheal and the bronchial region after inhalation, from where they are transported within hours by the so-called mucociliary clearance adoral and are mainly swallowed. This fraction reaches the gastrointestinal tract (GIT), where it comes into contact with gastric juice (Hamel et al., 1998). On the other hand particles less than $1 \mu \mathrm{m}$ can enter into the alveolar region of lungs where they interact with the lung fluid (Jianjum et al., 2010 and Song et al., 2011). For risk assessment of metal toxicity the determination of bio-accessible fractions is recommended. For this purpose extraction procedures with different leaching agents such as water, buffer solutions or synthetic body fluids were reported in literature. Since the chemical composition of these leaching agents is different it is expected that inconsistent amount of bio-accessible metal fractions is obtained via the use of applied leaching agents. Therefore, it is highly needed to evaluate the extraction efficiencies of various commonly used leaching agents for true estimation of bio-accessible trace metal fractions in APM.

In the present study, an in-vitro physiologically based extraction test (PBET) was employed for extraction of APM samples from Graz (Austria) and Karachi (Pakistan) with the leaching agents water, sodium chloride, ammonium acetate, ammonium citrate, synthetic gastric juice, artificial lysosomal fluid and Gamble solution, followed by measurement of resulting extracts using electrothermal vaporization 
inductively-coupled plasma atomic emission spectrometry (ETV-ICP-OES). Derived results were discussed in order to gain more detailed information about the extraction behavior of the investigated leaching agents.

\section{Materials and Methods}

\section{Reagents and materials}

High purity water was obtained by purifying de-ionized water (reverse osmosis/ion exchange combination Euro 20 plus, SG Water Systems, Germany) with an Easypure 2 system (Thermo Barnstead, USA). All used chemicals and reagents were of analytical reagent grade and were procured from Merck (Darmstadt, Germany). Pepsin from porcine stomach mucosa (456 units mg-1 solid) was purchased from Sigma Aldrich (Chemie $\mathrm{GmbH}$, Steinheim, Germany). Certified multielement standard solutions of $\mathrm{In}, \mathrm{As}, \mathrm{Ba}, \mathrm{Cd}, \mathrm{Co}, \mathrm{Cu}, \mathrm{Mn}, \mathrm{Ni}, \mathrm{Pb}$ and $\mathrm{Zn}$ $(1000 \mathrm{mg} / \mathrm{L})$ were purchased from Merck (Darmstadt, Germany) and diluted with $1 \% \mathrm{HNO}_{3}(\mathrm{v} / \mathrm{v})$ in order to prepare various working standard solutions. A $1 \mathrm{~mol} \mathrm{l}^{-1}$ solution of ammonium acetate was prepared by dissolving $77.0825 \mathrm{~g}$ weight in one litre of bi-distilled water and $\mathrm{pH}$ of the solution was maintained at 7 . Similarly, $0.1 \mathrm{~mol} \mathrm{l}^{-1}$ ammonium citrate solution was prepared by dissolving $22.619 \mathrm{~g}$ in one litre of high purity water and $\mathrm{pH}$ of the solution was maintained at 4.4 with the use of $\mathrm{HCl}$. The synthetic gastric juice was prepared according to a US Pharmacopeia methodology by dissolving $2 \mathrm{~g} \mathrm{NaCl}$ in $50 \mathrm{ml}$ of high purity water followed by addition of $7 \mathrm{ml}$ of conc. $\mathrm{HCl}$ in order to maintain $\mathrm{pH}$ of resulting solution at 2-2.5. To this solution, $3.2 \mathrm{~g}$ of pepsin were added, dissolved well and finally the volume was make up to 1 litre using bi-distilled water. Artificial lysosomal fluid and Gamble solution were prepared according to Colombo et al., 2008. Indium at level of $1 \mathrm{ppm}$ was also added to the prepared leaching agents as an internal standard in order to overcome non-spectral interferences as well as errors related to manual sample handling steps. The prepared leaching agents were stored in refrigerator at $4{ }^{\circ} \mathrm{C}$ until further use.

\section{Instrumentation}

An iCAP 6500 series ICP-OES spectrometer (Thermo Scientific, USA) has been used for simultaneous multielement analysis of $\mathrm{As}, \mathrm{Ba}, \mathrm{Cd}, \mathrm{Co}, \mathrm{Cu}, \mathrm{Mn}, \mathrm{Ni}, \mathrm{Pb}$, Zn. For sample introduction by electrothermal vaporization, an ETV system model 4000A ETV (Spectral Systems, Fürstenfeldbruck, Germany) was used corresponding in essence to a longitudinally heated graphite tube furnace. A detailed description of instrumentation and optimized method parameters can be found in Mukhtar and Limbeck, 2011.

\section{Collection of PM10 samples}

Sampling of size segregated APM samples (PM10) was performed at an urban site in Karachi, during March-April $2009(20 * 25 \mathrm{~cm})$ using high volume sampler, with an intake volume of approximately 1223 $\mathrm{m}^{3}$. Whereas sampling at Graz was done during July-August, $2006(147 * 147 \mathrm{~mm})$ with the help of an automated sampling device (Leckel, Germany) containing a PM10 pre-separation head, with an intake volume of Graz samples was $650 \mathrm{~m}^{3}$. Quartz fiber filters (PALL Life-sciences, Michigan, USA) were used as sampling substrates.

\section{In-Vitro physiological based extraction test (PBET) and determination of residual/total metal contents}

For determining the bio-accessible trace metal fraction present in APM, an in-vitro physiological based extraction test was performed. For this purpose, aliquots with a diameter of $10 \mathrm{~mm}$ were punched out from each collected PM10 sample. Six punches from each PM10 sample were taken into pre-cleaned polypropylene tubes followed by addition of $700 \mathrm{mg}$ of leaching agent. From each sample three replicates have been prepared with each type of leaching agent. Closed tubes were treated in an ultrasonic bath (Sonorex TK30, Bandelin, Germany) at $37^{\circ} \mathrm{C}$ for $1 \mathrm{~h}$ in order to extract soluble trace metal fractions. After cooling down the sample solutions to room temperature, the derived extracts were centrifuged (Hettich, Zentrifugen-EBA 20) at $5000 \mathrm{rpm}$ for $10 \mathrm{~min}$ for separation of undissolved material and remaining filter substrate. The supernatant clear sample solutions were transferred to new $3 \mathrm{ml}$ polypropylene tubes and stored until further analysis.

The remaining eight aerosol filter punches (diameter $12 \mathrm{~mm}$ ) were used for determination of total trace metal contents. For sample digestion the filter punches were transferred into pre-cleaned Bernas type Teflon lined bombs followed by addition of $1 \mathrm{ml}$ conc. $\mathrm{HNO}_{3}, 1 \mathrm{ml}$ $\mathrm{HCl}$ and $50 \mu \mathrm{l}$ of $\mathrm{HClO}_{4}$. The Teflon lined bombs were then placed in indigenously developed refractory oven and treated at $130{ }^{\circ} \mathrm{C}$ for $1 \mathrm{~h}$ in order to dissolve total metal contents. Finally, the temperature of the refractory oven was increased to $150{ }^{\circ} \mathrm{C}$ and maintained for other 30 min for evaporation of excessive amount of $\mathrm{HNO}_{3}$ and $\mathrm{HCl}$. After cooling the insoluble filter material including the small droplet of $\mathrm{HClO}_{4}$ remaining in the Teflon lined bombs were transferred in new PP tubes and diluted to a final mass of approximately $2 \mathrm{~g}$ with $1 \%(\mathrm{v} / \mathrm{v}) \mathrm{HCl}$. Simultaneously a defined amount of $\mathrm{In}$ as internal standard was added. After centrifugation the supernatant solutions were removed and stored in new PP tube at $4{ }^{\circ} \mathrm{C}$ until ananlysis.

\section{ETV-ICP-OES Analysis of standard solutions and PM10 samples}

Measurement of standard solution and prepared PM10 extracts was carried out according to Mukhtar and Limbeck, 2011. Briefly, $40 \mu 1$ of the prepared 


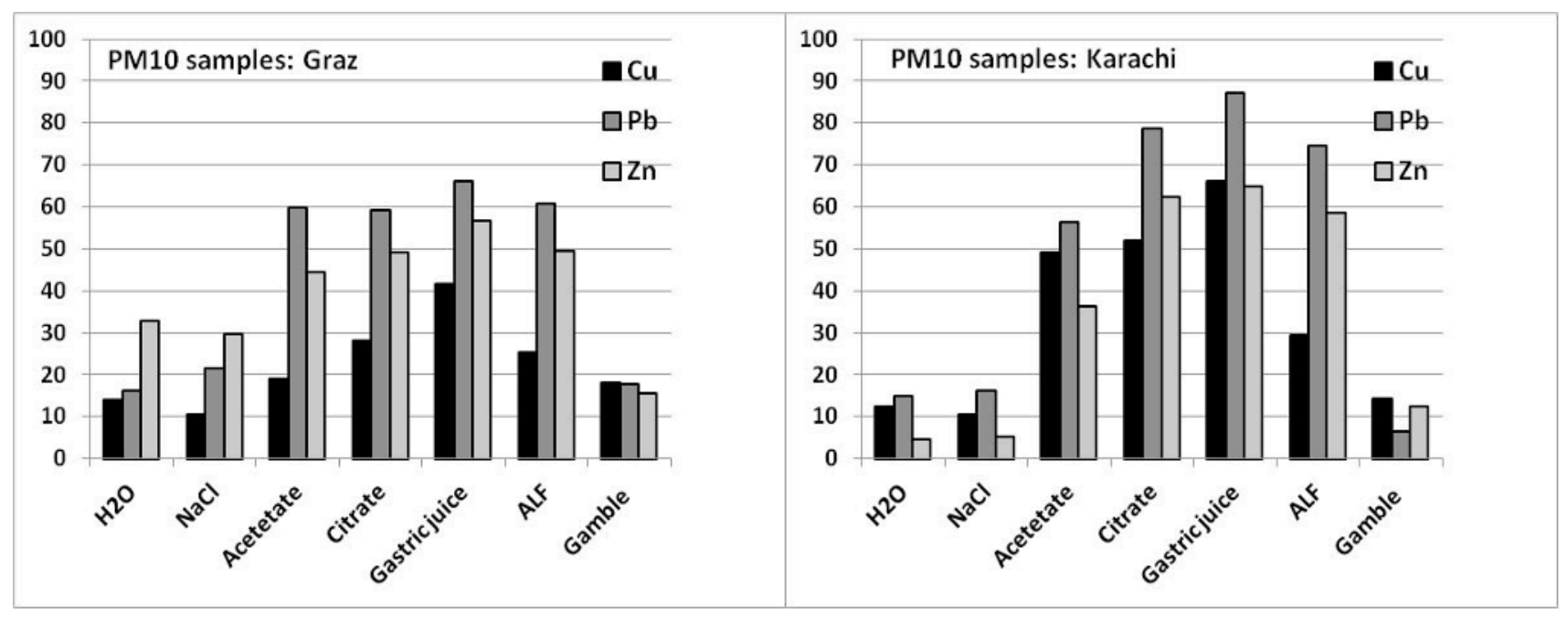

Fig. 1. Trace metal fractions extractable with different leaching agents (\%), results are average of twenty investigated PM10 samples.

extracts/digests were pipetted into precleaned graphite boats and dried using an IR-lamp. For analysis, the graphite boats were inserted into the graphite furnace tube of the ETV system and the furnace program was started by the ICP-OES software and the emission spectra of the vapor introduced into plasma was measured.

\section{Results and Discussion}

Total metal concentrations in PM10 samples from Karachi ranged from few ng $\mathrm{m}^{-3}$ to some hundred $\mathrm{ng} \mathrm{m}^{-3}$. The highest concentrations among the measured elements were observed for $\mathrm{Zn}$ ranging from $361 \mathrm{ng} \mathrm{m}^{-3}$ to $918 \mathrm{ng}$ $\mathrm{m}^{-3}$ whereas lowest concentrations were observed for trace element Cd varying from $1.9 \mathrm{ng} \mathrm{m}^{-3}$ to $4.2 \mathrm{ng} \mathrm{m}^{-3}$. As and Co revealed results below their detection limits i.e., less than $0.5 \mathrm{ng} \mathrm{m}^{-3}$. These results were found in accordance to literature findings as reported by Venkataraman et al., 2002, and Salam et al., 2003 for mega south Asian cities Mumbai and Dhaka respectively. Similar observations were found for PM 10 samples collected from Graz, with concentrations of $\mathrm{Zn}$ varying from $71 \mathrm{ng} \mathrm{m}^{-3}$ to $300 \mathrm{ng} \mathrm{m}^{-3}$ and $\mathrm{Cd}$ concentrations ranging from 0.9 to $1.5 \mathrm{ng} \mathrm{m}^{-3}$. These findings were in agreement with the results reported in literature from various sites in central Europe. For example, Limbeck et al., 2009 have reported concentrations of $\mathrm{Cd}$ and $\mathrm{Zn}$ in the order of $0.1 \mathrm{ng} \mathrm{m}^{-3}$ and $200 \mathrm{ng} \mathrm{m}^{-3}$ respectively in PM10 samples collected from various urban sites in Vienna. The results indicated clearly that atmosphere of Karachi is significantly more contaminated with toxic trace elements as compared to Graz.

Bio-accessible fractions were found to be lower than the corresponding total metal concentrations, indicating that only a fraction of metal is soluble in various leaching agents. Since bio-accessibility test has been performed with different leaching agents, variable amounts of bio-accessible trace metal fractions have been released which reflect differences in their ionic strength and composition. Therefore a question arises about the trueness of bio-accessible fractions. It was found that lowest bio-accessible trace metal fractions were obtained with the use of water and $\mathrm{NaCl}$ as compared to leaching agents with organic composition like synthetic gastric juice and artificial lysosomal fluid (Figure 1a and 1b). However, the Gamble solution released comparable quantities of bio-accessible trace metal fractions to that of water and $\mathrm{NaCl}$. Furthermore, the low leaching ability of Gamble solution as compared to synthetic gastric juice and artificial lysosomal fluid could be explained on the basis that it is neutral ( $\mathrm{pH}-7)$, thus the interaction of Gamble solution with PM10 metal particles is not so aggressive. In contrast, synthetic gastric juice and artificial lysosomal fluid being having complex organic nature and acidic $\mathrm{pH}$ causes the metals to release easily, thereby posing serious health risks when trace fractions become part of body fluid. It can also be deduced from above figure that the metal extracting behavior of applied leaching agents is quite similar for PM10 samples collected from two entirely different sites i.e., Graz (Central Europe) and Karachi (South Asia), indicating that bio-accessibility is element as well as leaching agent dependent.

Using synthetic gastric juice for assessment of bio-accessible trace metal fractions concentrations in PM10 ranging from $0.4 \mathrm{ng} \mathrm{m}^{-3}(\mathrm{Cd})$ to $714 \mathrm{ng} \mathrm{m}^{-3}(\mathrm{Zn})$ were found in aerosol samples collected in Karachi, whereas bio-accessible trace metal concentrations in PM10 samples from Graz varied from $0.3 \mathrm{ng} \mathrm{m}^{-3}(\mathrm{Cd})$ to $190 \mathrm{ng} \mathrm{m}^{-3}(\mathrm{Zn})$. Comparison of bio-accessible fraction in PM10 samples reported in present study with literature data is not possible, since current study is carried out for the first time where an attempt has been made to provide a guideline for estimation of actual bio-accessible trace metal fractions in APM.

\section{Conclusion}


In this study an attempt has been made for the first time in order to propose a model for the estimation of true bio-accessible trace metal fractions in APM which could be used as a guideline for future studies. In present study, an in-vitro PBET was applied for extraction of bio-accessible metal fractions present in APM using various leaching agents followed by subsequent measurement of gastric extracts using a recently developed ETV-ICP-OES procedure. The obtained results indicated severe differences in the extraction efficiencies of the investigated leaching agents. Highest bio-accessible trace metal fractions are obtained with the use of synthetic body fluids, lowest results were observed for water and sodium chloride solution. Generally it was found that the presence of organic complexing agent as well as acidic conditions improve the solubility of trace metals significantly. Therefore, for future studies it is highly recommended to use synthetic body fluids for estimation of bio-accessible trace metal fractions in APM, since they enable a more reliable assessment of bio-accessible trace metal fractions in PM10 than pure inorganic solutions.

\section{Acknowledgements}

Azam Mukhtar acknowledges the Higher Education Commission (HEC), Pakistan and the Austrian Exchange Service (ÖAD) for providing a Ph.D. scholarship for the period 2007-2011.

\section{References}

Limbeck A, Handler M, Puls C, Zibral J, Bauer H and Puxbaum $\mathrm{H}$. Impact of mineral components and selected trace metals on ambient PM10 concentrations. Atmos Environ 2009; 43: 530-538.

Mukhtar A and Limbeck A. Development of an
ETV-ICP-OES procedure for assessment of bio-accessible trace metal fractions in airborne particulate matter, J Anal At Spectrom 2011; 26: 2081-2088.

Colombo C, Monhemius A J and Plant JA. Platinum, palladium and rhodium release from vehicle exhaust catalysts and road dust exposed to simulated lung fluids, Ecotoxicology and Environmental Safety 2008; 71: 722-730.

Prieditis $\mathrm{H}$ and Adamson IYR. Comparative pulmonary toxicity of various soluble metals found in urban particulate dusts, Exp Lung Res 2002; 28: 563-572.

Jianjun N, Rasmussen P E, Hassan NM and Vincent R. Concentration Distribution and Bioaccessibility of Trace Elements in Nano and Fine Urban Airborne Particulate Matter: Influence of Particle Size, Water Air Soil Pollut 2010; 213: 211-225.

Michelozzi P, Forastiere F, Fusco D, Perucci CA, Ostro B, Ancona C and Palloti G. Air Pollution and Daily Mortality in Rome, Italy, Occup Environ Med 1998; 55: 605-610.

Hamel SC, Buckley B and Lioy PJ. Bioaccessibility of metals in soils for different liquid to solid ratios in synthetic gastric fluid, Environ Sci Technol 1998; 32: 358-362.

Song S, Lee K, Lee Y M, Lee JH, Lee S, Yu SD and Paek D. Acute health effects of urban fine and ultrafine particles on children with atopic dermatitis, Environ. Res., 3 (2011), pp. 394-399.

Salam A, Bauer H, Kassin K., Mohammad US, and Puxbaum H. Aerosol chemical characteristics of a mega-city in southeast Asia (Dhaka-Bangladesh), Atmos Environ 2003; 37: 2517-2528.

Venkataraman C, Reddy CK, Josson S, and Reddy M S. Aerosol size and chemical characteristics at mumbai, india, during the indoex-ifp (1999), Atmos Environ, 2002; 36: 1979-1991. 